\title{
Understanding the Pathobiology of Oral Lichen Planus
}

\author{
M. Carrozzo
}

Published online: 20 July 2014

(C) Springer International Publishing AG 2014

\begin{abstract}
Oral lichen planus (OLP) is a relatively common chronic inflammatory disease. A consistent body of evidence suggests that OLP is a predominantly T-cell mediated disease that shares clinical and histological features with chronic graft versus host disease. A putative genetic predisposition linked to cytokine polymorphisms has been revealed and some possible etiologic factors such as amalgam and hepatitis $\mathrm{C}$ virus have been studied in detail. In this review, an overview on the immunopathogenesis of OLP will be provided and a putative comprehensive hypothesis will be discussed in detail. Despite significant advances, many questions still remain concerning the etiology and pathogenesis of OLP.
\end{abstract}

Keywords Lichen planus · Oral lichen planus $\cdot$ Lichenoid lesions $\cdot$ Etiology $\cdot$ Pathogenesis

\section{Introduction}

Similar to the skin, the oral mucosa is affected by a variety of oral lichenoid lesions (OLL) that likely represent a common reaction pattern in response to extrinsic antigens, altered selfantigens or superantigens [1].

These diseases are linked together by the presence of a pattern of common histopathological elements that traditionally has been referred to as the "lichenoid tissue reaction" (LTR). These features include vacuolar changes of the basal keratinocytes intimately associated with a band-like array of mononuclear inflammatory cells consisting of activated $\mathrm{T}$ lymphocytes, macrophages and dendritic cells [1]. More

\section{Carrozzo ( $\bowtie)$}

Oral Medicine Department, Centre for Oral Health Research, School of Dental Sciences, University of Newcastle upon Tyne, Framlington Place, Newcastle upon Tyne NE2 4BW, UK

e-mail:marco.carrozzo@newcastle.ac.uk recently this histological pattern has been defined as "interface dermatitis" [2].

Oral lichen planus (OLP) is the prototype of OLL [1]. Despite the lack of good epidemiological data, OLP is thought to be relatively common, affecting approximately $1-2 \%$ of the population. OLP lesions are chronic and rarely undergo spontaneous remission. OLP most commonly affects middleaged females, without any apparent racial predilection [3].

The distinctive OLP clinical manifestations are represented by rarely symptomatic bilaterally located white papules that coalesce to form either a reticular, annular or plaque-like pattern, the so-called Wickham's striae. However, OLP can also manifest with erythematous and erosive/ulcerative lesions that can cause a varying degree of discomfort [3].

OLP is histologically characterized by dense, band-like, subepithelial lympho-histiocytic infiltrate, increased numbers of intra-epithelial lymphocytes, and degeneration of basal keratinocytes which form eosinophilic colloid (civatte, hyaline, cytoid) bodies, also called Russell bodies [4]. Epithelial basement membrane changes are common in OLP and include either breaks, branches or duplications. Degeneration of basement membrane causes weaknesses at the epithelialconnective tissue interface which may result in histological cleft formation (Max-Joseph space) and, rarely, clinical blistering of the oral mucosa (bullous lichen planus). Parakeratosis, acanthosis and 'saw-tooth' rete peg formation may be seen but they are more common on the skin [5].

\section{Etiology}

OLP is unlikely to be caused by a single antigen. Studies of $\mathrm{T}$ cell receptor variable region genes from lesional OLP $\mathrm{T}$ cells have not shown the use of a restricted number of different variable region genes [6]. In a minority of patients, 
precipitating factors have been identified, including dental materials, drugs, stress, and infectious agents [7].

Dental restorative materials thought to cause OLP/OLL include amalgam, composite resin, cobalt, and gold [3]. Of these however, amalgam has been the most deeply studied. Amalgam is supposed to cause a delayed hypersensitivity reaction (Coombs and Gell classification type IV) as a result of low-level mercury exposure, particularly when there has been direct contact between oral mucosa and mercury-containing amalgam fillings [8]. However, an animal model has failed to definitively prove that amalgam fillings can cause OLCL [9]. Moreover, evidence is patchy on the benefits of routine removal of all amalgam restorations in patients with OLP/OLL [7]. Another possible explanation for OLP/OLL related to dental restorations may be an immunological or toxic reaction to plaque accumulation on the surface of the restoration and such lesions may disappear after improvements in oral hygiene [7].

A systematic review stated that there is sufficient evidence that beta-blockers, methyldopa, penicillamine, quinidine, and quinine play a role in OLP, while non-steroidal antiinflammatory agents should also be considered causative [10]. The list of medication causing OLP/OLL is increasing but many of these reports have only been based on sporadic cases [11].

Stress is widely acknowledged to be an important etiological factor in OLP, but there have been remarkably few studies and most of these are not of high quality. Indeed, the chronic discomfort that can afflict patients with OLP can, in itself, be a stressing factor and may partially explain any documented association [3].

Infectious agents that have been suggested as triggering OLP include Herpes simplex virus 1, Epstein-Barr virus, Cytomegalovirus, Human Herpes virus 6 and virus 7, Human Papilloma Virus (HPV), Hepatitis C virus (HCV), and Helicobacter Pylori [12]. However, only for HPV and $\mathrm{HCV}$ is there more than anedoctal evidence. A recent metaanalysis showed that the risk estimates for the association with HPV for OLP patients was 5.12 (95\% Confidence intervals: 2.40-10.93). However, this study highlighted significant differences according to the detection methods used, and emphasized that any causative effect of HPV on OLP should be proven. Indeed, a possible explanation for the association could be that ulcerations, frequently seen in OLP, could make a lesion more susceptible for HPV infection. Another potential reason could be the chronic use of steroids, which may induce immune suppression and facilitate HPV replication [13].

Probably the best available evidence of the involvement of any extrinsic factor in the pathogenesis of OLP pathogenesis is in regards to HCV. Three recent independent meta-analyses provide robust epidemiological evidence supporting the link between OLP and HCV [7]. Moreover, the virus may replicate in the oral mucosa and attract HCV-specific T lymphocytes $[14 \cdot \bullet, 15 \bullet \cdot]$.

Most idiopathic cutaneous LP world-wide is related to the HLA-DR1 (DRB1*0101 allele), whereas in Italy, HCVrelated OLP appears to be particularly associated with the HLA class II allele HLA-DR6. Moreover, a significant association was found between erosive OLP and HLA-DR3 allele $[16,17]$.

\section{A T-cell mediated disease}

A strong body of evidence suggest that lichen planus (LP) is a T-cell-mediated disease. When autoreactive T-cells were injected into the footpads of syngeneic mice, they produced a histopathological picture indistinguishable from that of LP [18••]. Moreover, patients with chronic graft-vs.-host disease (cGVHD) may develop cutaneous and oral lesions clinically and histopathologically indistinguishable to those of OLP [19-21]. The lymphocytic infiltrate in OLP is composed almost exclusively of T-cells. Most lymphocytes in the lamina propria are CD4+ [22-24], and the majority of T-lymphocytes within the epithelium are activated CD8+ lymphocytes $[22$, $23,25,26]$. There are increased numbers of Langerhans cells (LCs) in OLP lesions with up-regulated MHC class II expression that are also expressed by keratinocytes [24, 27-29].

Conversely, OLP lesions contain few B-cells or plasma cells and minimal deposits of immunoglobulin or complement. Moreover, only a minor fraction $(<2 \%)$ of $\mathrm{CD} 3+$ cells in OLP co-expressed the CD94 marker, indicating that they are NK cells $[30 \bullet$. The killer cell immunoglobulin-like receptor (KIR) genes that encode a family of inhibitory and activating receptors mainly expressed on NK cells, also seem not to be involved in the pathogenesis of OLP [31].

In OLP inflammatory infiltrate there is an enrichment of CD45RO memory $\mathrm{T}$ cells that predominantly express Th1 cytokine [32]. Particularly IFN- $\gamma$ and TNF- $\alpha$ were found consistently overproduced in OLP [33•, 34, 35•]; whereas for other cytokines, such as IL-6, IL-8 and IL-10, the data are still controversial [33•, 34, 35•, 36-52, 53・•, 54-65] (Table 1). The absence of eosinophils in OLP inflammatorycell infiltrate indirectly confirms the dominance of Th1 cytokine pattern [2].

However, recently it has been suggested that some of the Th1 T-cells in OLP could in reality be Th0 lymphocytes, as they seem to produce Th2-type cytokines (such as IL-4, IL-5, and IL-13), together with IFN- $\gamma$ [43]. The same study also suggested a possible role for Th17 lymphocytes in erosive OLP [43].

CD4+CD25+ Forkhead box protein 3 (Foxp3+) regulatory $\mathrm{T}$ cells are possibly also important in OLP $[42,66]$.

A key, and probably early, event in LP, is the genetically induced increased production of Th1 cytokines that seems 


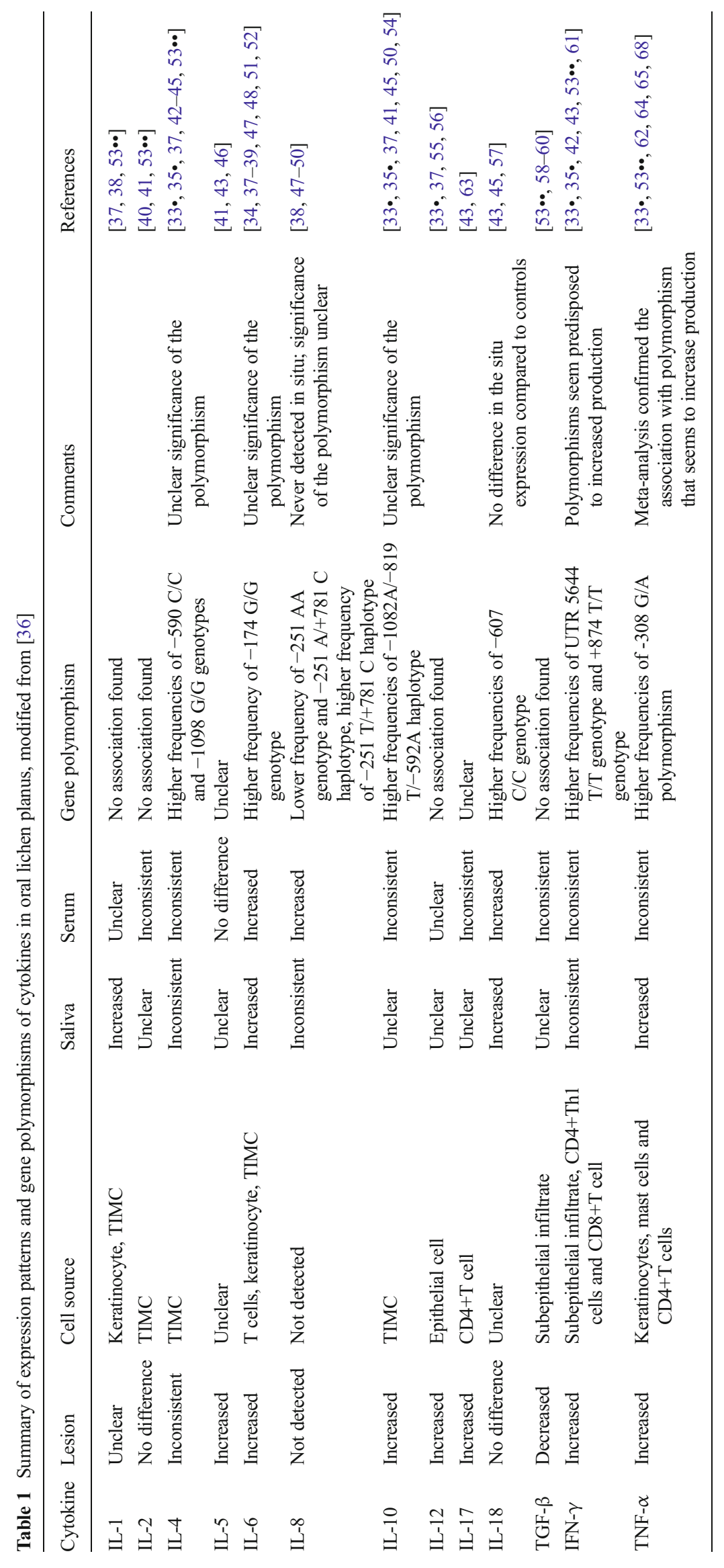


peculiar to patients without $\mathrm{HCV}$ infection $[53 \bullet \bullet, 67]$. A recent meta-analysis has confirmed that TNF- $\alpha-308$ G/A polymorphism may be a risk factor for HCV-negative OLP patients and those with mixed ethnicity [68]. Cytokine polymorphisms appear to govern whether lesions develop in the mouth in isolation (IFN- $\gamma$ associated), or in conjunction with skin lesions (TNF- $\alpha$ associated) [53••].

Another key event in OLP pathogenesis is the recruitment of different subsets of denditric cells (DCs), such as Langerhans cells, myeloid and plasmacytoid DCs, possibly through the expression of the chemotacting agonist chemerin by endothelial cells lining blood vessels [30••]. Plasmacytoid dendritic cells represent the main IFN- $\alpha$ producers among leukocytes, and this cytokine may induce cytotoxicity, activating natural killer/T cytotoxic cells or FasL-mediated apoptosis, all phenomena known to occur in OLP. MxA, an IFNa-inducible protein [69], has been shown to be expressed within the inflammatory infiltrate, indicating the active production of IFN- $\alpha$ in OLP biopsy specimens. Moreover, IFI27, another IFN- $\alpha$-inducible protein, has been demonstrated to be up-regulated in LP [70].

Antigens presented by MHC class II are processed through an endosomal cellular pathway, whereas antigens presented by MHC class I are processed through a cytosolic cellular pathway. MHC class I antigen presentation alone may result in a quick cytotoxic T-cell response, as seen in some oral herpetic infections and recurrent aphthous stomatitis. Conversely, MHC class II antigen presentation alone may generate Th1CD4+ T-cells that in the absence of MHC class I antigen presentation to $\mathrm{CD} 8+$ cells, would be cytotoxically inert. Hence, the putative antigen presented by MHC class II to CD4+helper T cells in oral LP may differ from that presented by MHC class I to CD8+ cytotoxic T cells (Fig. 1). The second antigen could be a self-antigen such as a heat shock protein induced on basal keratinocytes via innate immune response activation $[12,71 \bullet]$. Alternatively, a single antigen may gain access to both the endosomal and cytosolic cellular pathways of antigen presentation. For example, some viruses encode proteins. Notably, recruitment of HCV-specific CD4+ and/or $\mathrm{CD} 8+\mathrm{T}$ cells has been demonstrated in OLP tissue [15••].

Attraction and migration of the activated $T$ cells to the oral epithelium is further enhanced by intercellular adhesion molecules (ICAM-1 and VCAM), upregulation of epithelial basement membrane extracellular matrix proteins (collagen types IV and VII, laminin and integrins), and potentially CXCR3 and CCR5 signaling pathways [72]. Binding of $\mathrm{T}$ cells to keratinocytes and IFN- $\gamma$, and subsequent up-regulation of $\mathrm{p} 53$, matrix metalloproteinase (MMP) 1, and MMP38 leads to apoptosis, culminating in destruction of the epithelial basal cells [73]. However, according to a recent authoritative review, the primary morphological changes seen in the epidermal basal layer in OLP is more suggestive of necrosis, rather than apoptosis [2]. There are virtually no positive markers for cellular necrosis that have been characterized (predominantly in negative terms) by the absence of markers of apoptosis. Some data suggest that liquefaction degeneration seen in OLP and traditionally considered as a morphological expression of $\mathrm{T}$ lymphocyte attack, does not unequivocally indicate apoptosis [74].

The chronic course of OLP may be due to the activation of the inflammatory mediator NF-kB, and the inhibition of the TGF control pathway (TGF-b/smad), which may cause keratinocyte hyperproliferation leading to development of the white lesions $[75 \bullet, 76]$.
Fig. 1 Hypothesis for the immunopathogenesis of oral LP, modified from [12]

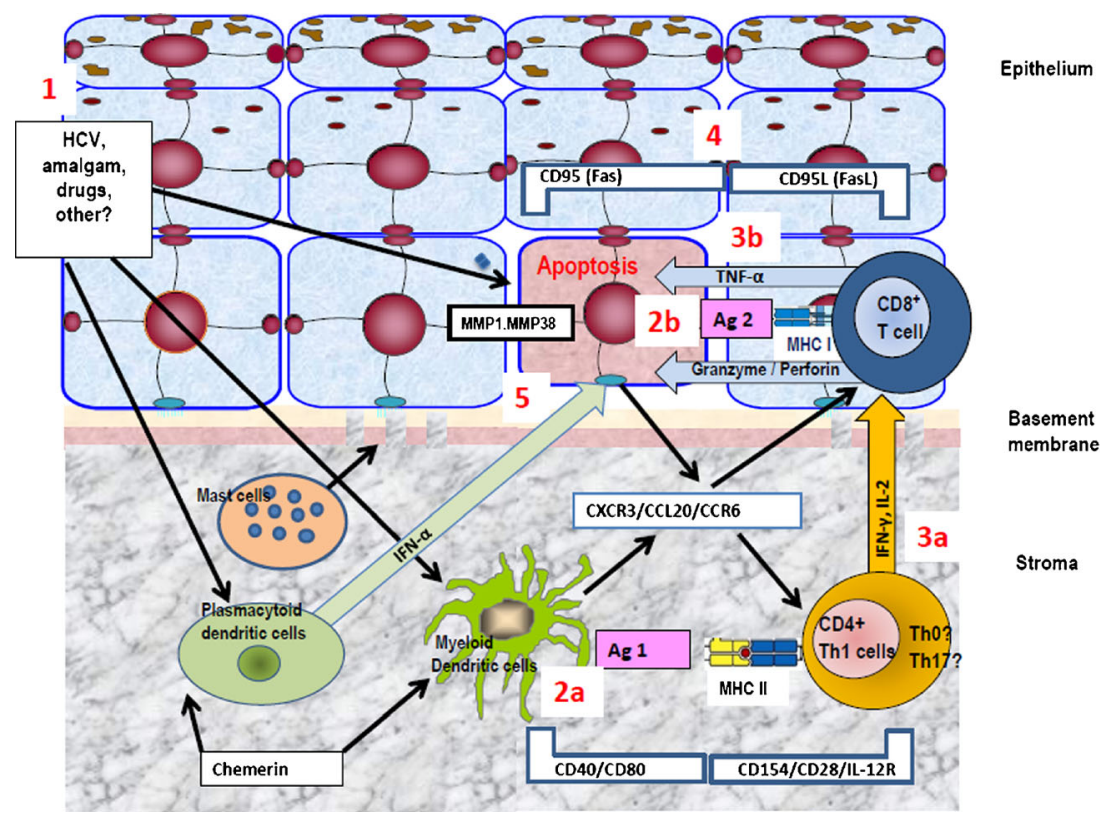




\section{A unifying hypothesis}

A unifying model of OLP pathogenesis, originally proposed by in 2002 and modified in 2005 by Sugerman et al. [12, 71•], is presented on Fig. 1 [12]. Antigen presenting cells (APCs), which can be either stromal dendritic cells or epidermal Langerhans cells, and basal keratinocytes are "activated" for example by viral infection (e.g., HCV), systemic drugs, contact sensitivity (e.g., amalgam), or an unidentified agent (Fig. 1-1). Activated APCs and keratinocytes secrete chemokines, such as CXCR3/CCL20/CCR6 (Ichimura et al., 2006), that attract lymphocytes into the developing OLP lesion. Plasmacytoid dendritic cells could amplify the activating effects of such stimuli via IFN- $\alpha$ production (Santoro et al., 2005).

Activated APCs present antigen associated with MHC class II to CD4+ T cells (Fig. 1-2a). Activated basal keratinocytes present antigen associated with MHC class I to CD81 T cells (Fig.1-2b). Co-stimulatory signals such as CD40 and CD80 co-expression and IL-12 secretion by MHC class II dendritic APCs and binding to CD154, CD28, and IL-12R, respectively, on the CD4+ T-cell promotes a $\mathrm{T}$ helper-1 (Th1) CD4+ T-cell response. Th1 CD4+ helper T cells secrete IL-2 and IFN-gamma (Fig. 1-3a), which bind their respective receptors on CD8+ $\mathrm{T}$ cells (Fig. 1-3b). It is possible that the recently described Th0 and/or Th-17 cell might play a role at this stage, the latter particularly on erosive OLP.

Activated antigen-specific CD8+ cytotoxic T cells express FasL or secrete granzyme B or TNF- $\alpha$ (Fig. 1-4) that trigger basal keratinocyte apoptosis (Fig. 1-5). Cytotoxic and pro-apoptotic mediators/stimuli expressed by fully activated cytotoxic CD8 T cells (i.e., granzyme, perforin, fas ligand) could then mediate the basal cell layer apoptosis in OLP.

The pro inflammatory milieu associated with degranulated mast cells might play a role in helping $\mathrm{T}$ cells breach the epidermal basement membrane in OLP lesions.

\section{Conclusions}

The pathogenic mechanism of OLP is now partially understood, with the recognition that this disease shares clinical and histological features with cGVHD. A putative genetic predisposition linked to cytokine polymorphisms has been revealed and some possible etiologic factors (namely amalgam and $\mathrm{HCV}$ ) have been studied in detail. However, a number of important unanswered questions need to be addressed. For example, does the OLP antigen vary from site to site or patient to patient? What is the initial event in OLP lesion formation? Do keratinocytes in OLP undergo necrosis or apoptosis?
Answers to these and other questions would be greatly facilitated by the development of novel animal or experimental models of LTR, mainly focused on the oral cavity.

\section{Compliance with Ethics Guidelines}

Conflict of Interest Dr. Marco Carrozzo declares no potential conflicts of interest.

Human and Animal Rights and Informed Consent This article does not contain any studies with human or animal subjects performed by any of the authors.

\section{References}

Papers of particular interest, published recently, have been highlighted as:

- Of importance

-. Of major importance

1. Khudhur A, Di Zenzo G, Carrozzo M. Oral lichenoid tissue reactions: diagnosis and classification. Expert Rev Mol Diagn. 2014;14 (2):169-84.

2. Sontheimer R. Lichenoid tissue reaction/interface dermatitis: clinical and histological perspectives. J Invest Dermatol. 2009;129(5): 1088-99.

3. Carrozzo M, Thorpe R. Oral lichen planus: a review. Minerva Stomatol. 2009;58(10):519-37.

4. Helander S, Rogers 3rd R. The sensitivity and specificity of direct immunofluorescence testing in disorders of mucous membranes. J Am Acad Dermatol. 1994;30(1):65-75.

5. Eisen D, Carrozzo M, Sebastian JVB, Thongprasom K. Number V Oral lichen planus: clinical features and management. Oral Dis. 2005;11(6):338-49.

6. Thomas DW, Stephens P, Stephens M, Patten DW, Lim SH. T-cell receptor $\mathrm{V}$ beta usage by lesional lymphocytes in oral lichen planus. J Oral Pathol Med. 1997;26(3):105-9.

7. Baccaglini L, Thongprasom K, Carrozzo M, Bigby M. Urban legends series: lichen planus. Oral Dis. 2013;19(2):128-43.

8. McParland H, Warnakulasuriya S. Oral lichenoid contact lesions to mercury and dental amalgam-a review. J Biomed Biotechnol. 2012;2012:589569. doi:10.1155/2012/589569.

9. Dunsche A, Frank M, Lüttges J, Açil Y, Brasch J, Christophers E, et al. Lichenoid reactions of murine mucosa associated with amalgam. Br J Dermatol. 2003;148(4):741-8.

10. Thompson D, Skaehill P. Drug-induced lichen planus. Pharmacotherapy. 1994;14(5):561-71.

11. McCartan B, McCreary C. Oral lichenoid drug eruptions. Oral Dis. 1997;3(2):58-63.

12. Lodi G, Scully C, Carrozzo M, Griffiths M, Sugerman PB, Thongprasom K. Current controversies in oral lichen planus: report of an international consensus meeting. Part 1. Viral infections and etiopathogenesis. Oral Surg Oral Med Oral Pathol Oral Radiol Endod. 2005;100(1):40-51.

13. Syrjänen S, Lodi G, von Bültzingslöwen I, Aliko A, Arduino P, Campisi G, et al. Human papillomaviruses in oral carcinoma and oral potentially malignant disorders: a systematic review. Oral Dis. 2011;17 Suppl 1:58-72.

14.• Carrozzo M, Quadri R, Latorre P, Pentenero M, Paganin S, Bertolusso G, et al. Molecular evidence that the hepatitis $\mathrm{C}$ virus 
replicates in the oral mucosa. J Hepatol. 2002;37(3):364-9. Positive and negative $\mathrm{HCV}$ strands were found in OLP tissues.

15.• Pilli M, Penna A, Zerbini A, Vescovi P, Manfredi M, Negro F, et al. Oral lichen planus pathogenesis: a role for the $\mathrm{HCV}$-specific cellular immune response. Hepatology. 2002;36(6):1446-52. Hepatitis $C$ virus-specific CD4 cells may be recruited in OLP lesions.

16. Jontell M, Stahlblad PA, Rosdahl I, Lindblom B. HLA-DR3 antigens in erosive oral lichen planus, cutaneous lichen planus, and lichenoid reactions. Acta Odontol Scand. 1987;45(5):309-12.

17. Carrozzo M, Francia Di Celle P, Gandolfo S, Carbone M, Conrotto $\mathrm{D}$, Fasano ME, et al. Increased frequency of HLA-DR6 allele in Italian patients with hepatitis $\mathrm{C}$ virus-associated oral lichen planus. Br J Dermatol. 2001;144(4):803-8.

18.• Saito K, Tamura A, Narimatsu H, Tadakuma T, Nagashima M. Cloned auto-Ia-reactive $\mathrm{T}$ cells elicit lichen planus-like lesion in the skin of syngeneic mice. J Immunol. 1986;137(8):2485-95. LP can be induced in skin of syngeneic mice by transferring Tcells.

19. Farmer E. The histopathology of graft-versus-host disease. Adv Dermatol. 1986;1:173-88.

20. Boyd A, Neldner K. Lichen Planus. J Am Acad Dermatol. 1991;25 (4):593-619.

21. Treister N, Duncan C, Cutler C, Lehmann L. How we treat oral chronic graft-versus-host disease. Blood. 2012;120(17):3407-18.

22. Matthews JB, Scully CM, Potts AJ. Oral lichen planus: an immunoperoxidase study using monoclonal antibodies to lymphocyte subsets. Br J Dermatol. 1984;111(5):587-95.

23. Kilpi A. Characterization of mononuclear cells of inflammatory infiltrates in oral tissues. A histochemical and immunohistochemical study of labial salivary glands in Sjogren's syndrome and of oral lesions in systemic lupus erythematosus and in lichen planus. Proc Finn Dent Soc. 1988;84 Suppl 3:1-93.

24. Farthing PM, Cruchley AT. Expression of MHC class II antigens (HLA DR, DP and DQ) by keratinocytes in oral lichen planus. J Oral Pathol Med. 1989;18(5):305-9.

25. Kilpi AM. Activation marker analysis of mononuclear cell infiltrates of oral lichen planus in situ. Scand J Dent Res. 1987;95(2): 174-80.

26. Jungell P, Konttinen YT, Nortamo P, Malmstrom M. Immunoelectron microscopic study of distribution of T cell subsets in oral lichen planus. Scand J Dent Res. 1989;97(4):361-7.

27. Rich AM, Reade PC. A quantitative assessment of Langerhans cells in oral mucosal lichen planus and leukoplakia. Br J Dermatol. 1989;120(2):223-8.

28. Farthing PM, Matear P, Cruchley AT. Langerhans cell distribution and keratinocyte expression of HLADR in oral lichen planus. J Oral Pathol Med. 1992;21(10):451-5.

29. Walsh LJ, Ishii T, Savage NW, Gemmell E, Seymour GJ. Immunohistologic analysis of epithelial cell populations in oral lichen planus. J Oral Pathol Med. 1990;19(4):177-81.

30.• Parolini S, Santoro A, Marcenaro E, Luini W, Massardi L, Facchetti $\mathrm{F}$, et al. The role of chemerin in the colocalization of NK and dendritic cell subsets into inflamed tissues. Blood. 2007;109(9): 3625-32. Explains dendritic cell recruitment in OLP.

31. Carrozzo M, Elia A, Mereu V, Dametto E, Fasano M, Broccoletti R, et al. HLA-C/KIR genotypes in oral lichen planus patients infected or non-infected with hepatitis C virus. Oral Dis. 2011;17(3):30913.

32. Walton LJ, Macey MG, Thornhill MH, Farthing PM. Intraepithelial subpopulations of $\mathrm{T}$ lymphocytes and Langerhans cells in oral lichen planus. J Oral Pathol Med. 1998;27(3):116-23.

33. Simark-Mattsson C, Bergenholtz G, Jontell M, Eklund C, Seymour GJ, Sugerman PB, et al. Distribution of interleukin$2,-4,-10$, tumour necrosis factor-alpha and transforming growth factor-beta mRNAs in oral lichen planus. Arch Oral Biol. 1999;44(6):499-507. Th1 cytokines are mainly overexpressed in OLP.
34. Karagouni EE, Dotsika EN, Sklavounou A. Alteration in peripheral blood mononuclear cell function and serum cytokines in oral lichen planus. J Oral Pathol Med. 1994;23(1):28-35.

35. Khan A, Farah CS, Savage NW, Walsh LJ, Harbrow DJ, Sugerman PB. Th1 cytokines in oral lichen planus. J Oral Pathol Med. 2003;32 (2):77-83. Thelper 1 immune response promote CD8+ cytotoxic Tcell activity in $O L P$.

36. Lu R, Zhang J, Sun W, Du G, Zhou G. Inflammation-related cytokines in oral lichen planus: an overview. J Oral Pathol Med. 2013. doi:10.1111/jop.12142.

37. Yamamoto T, Osaki T. Characteristic cytokines generated by keratinocytes and mononuclear infiltrates in oral lichen planus. J Invest Dermatol. 1995;104(5):784-8.

38. Rhodus NL, Cheng B, Myers S, Bowles W, Ho V, Ondrey F. A comparison of the pro-inflammatory, NF-kappaB-dependent cytokines: TNF-alpha, IL-1-alpha, IL-6, and IL-8 in different oral fluids from oral lichen planus patients. Clin Immunol. 2005;114(3):278-83.

39. Barkokebas A, de Albuquerque TCA, de Souza PR, Gomez RS, Xavier GM, Ribeiro CM, et al. Mannose-binding lectin gene (MBL-2) polymorphism in oral lichen planus. Clin Oral Investig. 2011;15(5):699-704.

40. Hu J, Zhang J, Cui J, Liang X, Lu R, Du G, et al. Increasing CCL5/CCR5 on CD4+ T cells in peripheral blood of oral lichen planus. Cytokine. 2013;62(1):141-5.

41. Pekiner F, Demirel G, Borahan M, Ozbayrak S. Cytokine profiles in serum of patients with oral lichen planus. Cytokine. 2012;60(3): $701-6$.

42. Tao X, Xia J, Chen X, Wang H, Dai Y, Rhodus N, et al. FOXP3 T regulatory cells in lesions of oral lichen planus correlated with disease activity. Oral Dis. 2010;16(1):76-82.

43. Piccinni M, Lombardelli L, Logiodice F, Tesi D, Kullolli O, Biagiotti R, et al. Potential pathogenetic role of Th17, Th0, and Th2 cells in erosive and reticular oral lichen planus. Oral Dis. 2014;20(2):212-8.

44. Liu W, Dan H, Wang Z, Jiang L, Zhou Y, Zhao M, et al. IFNgamma and IL-4 in saliva of patients with oral lichen planus: a study in an ethnic Chinese population. Inflammation. 2009;32(3):176-81.

45. Bai J, Lin M, Zeng X, Zhang Y, Wang Z, Shen J, et al. Association of polymorphisms in the human IFN-gamma and IL-4 gene with oral lichen planus: a study in an ethnic Chinese cohort. J Interferon Cytokine Res. 2008;28(6):351-8.

46. Gotoh A, Hamada Y, Shiobara N, Kumagai K, Seto K, Horikawa T, et al. Skew in $\mathrm{T}$ cell receptor usage with polyclonal expansion in lesions of oral lichen planus without hepatitis $\mathrm{C}$ virus infection. Clin Exp Immunol. 2008;154(2):192-201.

47. Rhodus N, Cheng B, Ondrey F. Th1/Th2 cytokine ratio in tissue transudates from patients with oral lichen planus. Mediat Inflamm. 2007;2007:19854

48. Zhang Y, Lin M, Zhang S, Wang Z, Jiang L, Shen J, et al. NFkappaB-dependentcytokines in saliva and serum from patients with oral lichen planus: a study in an ethnic Chinese population. Cytokine. 2008;41(2):144-9.

49. Little M, Griffiths C, Watson R, Pemberton M, Thornhill M. Oral mucosal keratinocytes express RANTES and ICAM-1, but not interleukin- 8 , in oral lichen planus and oral lichenoid reactions induced by amalgam fillings. Clin Exp Dermatol. 2003;28(1):64-9.

50. Dan H, Liu W, Zhou Y, Wang J, Chen Q, Zeng X. Association of interleukin- 8 gene polymorphisms and haplotypes with oral lichen planus in a Chinese population. Inflammation. 2010;33 (2):76-81.

51. Kho H, Chang J, Kim Y, Kim Y. MUC1 and Toll-like receptor-2 expression in burning mouth syndrome and oral lichen planus. Arch Oral Biol. 2013;58(7):837-42.

52. Xavier G, de Sa A, Guimaraes A, da Silva T, Gomez R. Investigation of functional gene polymorphisms interleukin-1beta, interleukin-6, interleukin-10 and tumor necrosis factor in 
individuals with oral lichen planus. J Oral Pathol Med. 2007;36(8): 476-81.

53.• Carrozzo M, de Capei MU, Dametto E, Fasano ME, Arduino P, Broccoletti R, et al. Tumor necrosis factor-alpha and interferongamma polymorphisms contribute to susceptibility to oral lichen planus. J Invest Dermatol. 2004;122(1):87-94. First research suggesting cytokine polymorphisms involvement in OLP pathogenesis.

54. Zhou G, Zhang J, Ren X, Hu J, Du G, Xu X. Increased B7-H1 expression on peripheral blood $\mathrm{T}$ cells in oral lichen planus correlated with disease severity. J Clin Immunol. 2012;32(4):794-801.

55. Ohno S, Tateishi Y, Tatemoto Y, Morishita K, Sasabe E, Yamamoto T. Enhanced expression of Toll-like receptor 2 in lesional tissues and peripheral blood monocytes of patients with oral lichen planus. J Dermatol. 2011;38(4):335-44.

56. Kalogerakou F, Albanidou-Farmaki E, Markopoulos A, Antoniades D. Detection of T cells secreting type 1 and type 2 cytokines in the peripheral blood of patients with oral lichen planus. Hippokratia. 2008;12(4):230-5.

57. Zhang Y, Liu W, Zhang S, Dan H, Lu R, Wang F, et al. Salivary and serum interleukin-18 in patients with oral lichen planus: a study in an ethnic Chinese population. Inflammation. 2012;35(2):399-404.

58. Chen Y, Zhang W, Geng N, Tian K, Jack Windsor L. MMPs, TIMP2 , and TGF-betal in the cancerization of oral lichen planus. Head Neck. 2008;30(9):1237-45.

59. Vered M, Fürth E, Shalev Y, Dayan D. Inflammatory cells of immunosuppressive phenotypes in oral lichen planus have a proinflammatory pattern of expression and are associated with clinical parameters. Clin Oral Investig. 2013;17(5):1365-73.

60. Taghavi Zenouz A, Pouralibaba F, Babaloo Z, Mehdipour M, Jamali Z. Evaluation of serum TNF-a and TGF-b in patients with oral lichen planus. J Dent Res Dent Clin Dent Prospects. 2012;6(4): 143-7.

61. Ghallab N, el-Wakeel N, Shaker O. Levels of salivary IFN-gamma, TNF-alfa, and TNF receptor-2 as prognostic markers in (erosive) oral lichen planus. Mediat Inflamm. 2010;2010:847632.

62. Kimkong I, Hirankarn N, Nakkuntod J, Kitkumthorn N. Tumour necrosis factor-alpha gene polymorphisms and susceptibility to oral lichen planus. Oral Dis. 2011;17(2):206-9.

63. Xie S, Ding L, Xiong Z, Zhu S. Implications of Th1 and Th17 cells in pathogenesis of oral lichen planus. J Huazhong Univ Sci Technol Med Sci. 2012;32(3):451-7.

64. Younes F, Quartey E, Kiguwa S, Partridge M. Expressionof TNF and the 55-kDa TNF receptor in epidermis, oral mucosa, lichen planus and squamous cell carcinoma. Oral Dis. 1996;2(1):25-31.

65. Sklavounou-Andrikopoulou A, Chrysomali E, Iakovou M, Garinis G, Karameris A. Elevated serum levels of the apoptosis related molecules TNF-alpha, Fas/Apo-1 and Bcl-2 in oral lichen planus. J Oral Pathol Med. 2004;33(7):386-90.

66. Shen Z, Gao X, Ma L, Zhou Z, Shen X, Liu W. Expression of Foxp3 and interleukin-17 in lichen planus lesions with emphasis on difference in oral and cutaneous variants. Arch Dermatol Res. 2014;306(5):441-6

67. Carrozzo M, Dametto E, Fasano ME, Arduino P, Bertolusso G, Uboldi de Capei F, et al. Cytokine gene polymorphisms in hepatitis C virus-related oral lichen planus. Exp Dermatol. 2007;16(9):7306.

68. Jin X, Wang J, Zhu L, Wang L, Dan H, Zeng X, et al. Association between $-308 \mathrm{G} / \mathrm{A}$ polymorphism in TNF- $\alpha$ gene and lichen planus: a meta-analysis. J Dermatol Sci. 2012;68(3):127-34.

69. Shaker O, Hantar N, El-Tahlawi S, El-Tawdi A, El-Hadidi H, Hantar S, et al. Detection of myxovirus resistance protein $\mathrm{A}$ in lichen planus lesions and its relationship to hepatitis $\mathrm{C}$ virus. $\mathrm{Br} \mathrm{J}$ Dermatol. 2009;160(5):980-3.

70. Suomela S, Cao L, Bowcock A, Saarialho-Kere U. Interferon a-inducible protein 27 (IFI) is upregulated in psoriatic skin and certain epithelial cancers. J Invest Dermatol. 2004;122 (3):717-21.

71. Sugerman PB, Savage NW, Walsh LJ, Zhao ZZ, Zhou XJ, Khan A, et al. The pathogenesis of oral lichen planus. Crit Rev Oral Biol Med. 2002;13(4):350-65. Comprehensive review on OLP pathogenesis.

72. Ichimura M, Hiratsuka K, Ogura N, Utsunomiya T, Sakamaki H, Kondoh T, et al. Expression profile of chemokines and chemokine receptors in epithelial cell layers of oral lichen planus. J Oral Pathol Med. 2006;35(3):167-74.

73. Kim SG, Chae CH, Cho BO, Kim HN, Kim HJ, Kim IS, et al. Apoptosis of oral epithelial cells in oral lichen planus caused by upregulation of BMP-4. J Oral Pathol Med. 2006;35(1):37-45.

74. Bascones-Ilundain C, Gonzalez-Moles MA, Esparza G, GilMontoya JA, Bascones-Martinez A. Significance of liquefaction degeneration in oral lichen planus: a study of its relationship with apoptosis and cell cycle arrest markers. Clin Exp Dermatol. 2007;32(5):556-63.

75. Santoro A, Majorana A, Bardellini E, Festa S, Sapelli P, Facchetti F. NF-kappaB expression in oral and cutaneous lichen planus. J Pathol. 2003;201(3):466-72. The different expression of NFkappaB might explain the different clinical courses of OLP and skin $L P$.

76. Karatsaidis A, Schreurs O, Axell T, Helgeland K, Schenck K. Inhibition of the transforming growth factor-b/Smad signaling pathway in the epithelium of oral lichen. J Invest Dermatol. 2003;121 (6):1283-90. 